\title{
Realism, Beyond Miracles
}

\author{
AXEL MUELLER AND ARTHUR FINE
}

Two things about Hilary Putnam have not changed throughout his career: some (including Putnam himself) have regarded him as a "realist" and some have seen him as a philosopher who changed his positions (certainly with respect to realism) almost continually. Apparently, what realism meant to him in the 1960s, in the late seventies and eighties, and in the nineties, respectively, are quite different things. Putnam indicates this by changing prefixes: scientific, metaphysical, internal, pragmatic, commonsense, but always realism. Encouraged by Putnam's own attempts to distinguish his views from one time to another, his work is often regarded as split between an early period of "metaphysical realism" (his characterization) and a later and still continuing period of "internal realism". Late Putnam is understood to be a view that insists on the primacy of our practices, while the early period is taken to be a view from outside these, a "God's Eye view". As Putnam himself stresses (1992b), this way of dividing his work obscures continuities, the most important of which is a continuing attempt to understand what is involved in judging practices of inquiry, like science, as being objectively correct. Thus Putnam's early and his current work appear to have more in common than the division between "early" and "late" suggests. In fact, Putnam's earlier writings owe much of their critical force to his adopting the pragmatic perspective of an open-minded participant in practices of empirical inquiry, a stance not explicitly articulated in these writings but rather taken simply as a matter of course. ${ }^{1}$ Thus insofar as Putnam's early writings defend a form of representational realism, they can be regarded as attempts to articulate a realist position at work inside our ordinary practices of making empirical judgments. For this reason, we begin our review of Putnam's realisms by extracting from the early writings a core of principles that carries over into his current work but underwent significantly different interpretations over time. The most consequential of these reinterpretations was Putnam's attempt to mold this core into "scientific realism", a development that called for leaving the pragmatic perspective of the earlier work in favor of a picture of a unique external reality that underlies all the 
claims we are entitled to regard as objective. Putnam's current position can then be seen, in his own words, as the attempt "to recover our ordinary notion of representation (and of a world of things to be represented)" (1994a, p. 300) without committing the "philosophical error of supposing that the term reality must refer to a single superthing" $(1999$, p. 9).

In the following, we proceed in these steps. First, we present Putnam's position from the late fifties to, say, the early seventies (secs. I-III). In these writings, Putnam excavates a realist core that participants in fallible practices of inquiry take for granted when they make and exchange factual claims. He does this by opposing a pragmatic perspective on public practices of inquiry to the antirealist reductions of empiricism. This core can be characterized by four basic assumptions (or presuppositions), which we lay out in the next section. Three of them connect reference, truth and objectivity, and we shall refer to them as the referential principles. The fourth concerns a publicly shared context for empirical inquiry, and we shall call this the environmental principle.

The second step we shall take is to discuss some of Putnam's reasons first to adopt and then to reject scientific realism (secs. IV-VI). The appearance of "scientific realism" in Putnam's pragmatic outlook marks the beginning of an extended period of reflection on realism. In spite of the fundamental role in inquiry of the presuppositions just mentioned, any attempt to take them for granted faces a challenge from the fact, emphasized by Putnam, that we can always go wrong. Indeed, over time we have seen well-entrenched theoretical claims come to be regarded as false and terms once explanatorily fruitful lose their reference. Thus the question arises of whether the core presuppositions are merely illusions, and whether theoretical claims we make are, as vulgar instrumentalism suggests, merely tools for organizing experience. Are empirical descriptions really capable of objective truth or falsity? In reaction to this challenge, Putnam experimented with a defense of these core commitments by re-presenting them as a substantive view alternatively called "scientific realism" or "metaphysical realism". According to it, the correspondence of our true claims and referential terms with a unique mind-independent reality explains the success and the communicability of scientific claims. Thus, the referential principles are embedded in a picture of objective knowledge that tries to account for the objectivity (as opposed to the acceptance) of our empirical beliefs, and the environmental principle is substituted for by the picture of a mindindependent reality. We shall see, as Putnam came to realize, that such a defense fails badly; that it neither lends support to realism nor excludes anti-realism; in particular, instrumentalism. 
Putnam's reaction to the failure is not to give up the referential principles, but to revert to the participant's perspective and to deepen his reflection on their use in evaluating empirical claims. In the course of this reflection he gradually dismantles the metaphysical realist picture of a mind-independent reality and recovers the environmental principle as its pragmatic counterpart. The final step in our presentation (sec. VII) will be to characterize some of the key features of Putnam's current work. This work undermines the realist picture without giving up the view that the correctness of empirical statements has an objective basis. The key element here is Putnam's insistence on the fact that, from the participant's perspective, there is no access to any reality but by describing it in a certain way - that is, by using certain conceptual systems. The idea of an absolutely mind-independent, totally unconceptualized reality, since indescribable, is also not usable for any purposes. The upshot is that our notion of a statement's objective correctness does not entail commitment to any theory-neutral domain, but only commitment to the public revisibility of our claims. Moreover, Putnam suggests that from ordinary language to high-level science there exist many different conceptual systems that are perfectly capable of describing a given situation in ways that can be and often are objectively correct. If we recognize that no particular system is forced upon us, this leads to pluralism. Pluralism is the basis of his "common-sense realism", which urges that as long as none of these systems accommodates the possibility that, in a given case, a statement and its contrary could be equally correct, all of these ways of describing our environment are on a par as far as objectivity is concerned. For any of these descriptions, to take them as empirical amounts to applying the referential principles. According to Putnam's current view, the use of referential semantics does not depend on relations of "correspondence", for instance, between our sentences and the facts themselves. It simply relies on disquotation. That allows us to subject each other's assertions to the usual inferential practices guiding our evaluation of empirical claims. By means of disquotation, each way of making correct empirical statements is in effect a way of organizing the situation into objects and properties. Putnam concludes that taking all the various systems that are applicable in a context as capable of issuing empirical statements is at the same time taking the entities, properties and relations denoted in any system to be as real as the ones in the others.

This constitutes his doctrine of "conceptual relativity", the view that in some cases there is more than one way to represent the same situation, none of which stands out as the best, because each is fully interpretable in terms of one another (even though, if simply joined, their existential commitments 
yield contradictions). Putnam uses cases of conceptual relativity to drive home the lesson that no "superthing", like the realist's picture of a mindindependent reality, is needed to ground objective judgments. Putnam's considered position thus finds a way to reconcile the core principles underlying his earliest views with a mature, reflective stance toward our practice of empirical inquiry. ${ }^{2}$

\section{BACKGROUND: GENERAL REVISIBILITY AND THE CONTEXTUAL APRIORI}

According to his own testimony at the time, and to recent self-evaluations, Putnam's earlier writings were not avowedly realist. ${ }^{3}$ Rather, he was attempting what he called a "mild rational reconstruction" (1992b, p. 349) of epistemic and interpretative practices. Those reconstructions sought to correct distortions of earlier "reconstructions" in the empiricist, anti-realist tradition. Putnam begins from the perspective of the practices and, in consequence, turns out to be what we shall call "anti-antirealist" on all relevant counts.

Putnam's rejection of empiricism is built on a pragmatic, fallibilist view of inquiry. This involves a presumption of general revisibility, and it is expressed by Putnam in the following way: "any principle in our knowledge can be revised for theoretical reasons" (1962a, p. 48). This idea is hedged by two caveats (which also help to distinguish him from Quine on this score): "unless it is really an analytic principle in the trivial sense", and "many principles resist refutation by isolated experimentation". With these caveats, revisibility embodies the pragmatist view that there is no guarantee for any statement held true that it cannot turn out to be false. In this general form, revisibility applies in different ways to statements at all levels, from framework principles to theoretical and observational statements.

In a second pragmatist move, Putnam's reconstruction takes the participants' perspective (and their normative judgments) into account. This leads him to complement revisibility by a notion of the contextual apriori, nicely expressed by his remark that "there are necessary truths in physics, but they can be revised if necessary.... [However,] scientists were perfectly correct to assign a special status to these statements.... It is the task of the methodologist to explain this special status, not to explain it away" (1965, pp. 88-92). More of a classical pragmatist than Quine, Putnam's criticism of the empiricist dichotomy between analytic and synthetic statements follows Dewey's rule that, wherever we find reasonable distinctions, we should 
neither replace them by dichotomies nor fail to make them. Consequently, unlike Quine, Putnam does not conclude that there is no important distinction to be drawn within given bodies of belief just because each belief can be revised. Rather, his reconstruction stresses that revisibility only makes sense in practice when appropriate conditions for revision are provided (1962a, p. 42). ${ }^{4}$ Where this is not the case, we take it for granted that the statements in question constitute objective knowledge and, if they contain extralogical vocabulary, even knowledge of the most abstract structures of the world. The complement to fallibilism in Putnam's pragmatism is a healthy confidence in the claims we have no specific reasons to doubt. ${ }^{5}$

When Putnam looks at inquiry from the perspective of a participant, he excavates a core of central assumptions that participants take for granted when they make and exchange factual claims. From this perspective, the anti-realist reductions of empiricism fail to do justice to the fallibilist attitude with which inquirers develop their theories. The central assumptions Putnam excavates are these: (1) normally, terms used descriptively in public practices of making and exchanging empirical claims refer; (2) statements at all levels in a system of empirical knowledge state facts, and are taken as objectively true and revisable as long as they are in use; (3) descriptively used terms can preserve reference over dramatic differences in theory and belief; (4) there is a publicly shared environment in which applications of terms and theories take place. The referential principles are (1)-(3). The environmental principle is (4).

We begin our reconstruction in section II by showing how the connection posited in (2) between objective truth and revisibility emerges from Putnam's rejection of the analytic-synthetic distinction and his discussion of the framework assumptions that are taken for granted in the formation of empirical judgments. After this, we will show in section III how the other principles emerge from considerations regarding changes in the epistemic conditions governing the application of empirical terms.

\section{FRAMEWORKS AND CONTEXTS OF REVISION}

In "The Analytic and the Synthetic", Putnam says "overworking the analytic-synthetic distinction is [a] ... root of what is most distorted in the writings of conventional [logical positivist] philosophers of science" (1962a, p. 33). This said, he warns against the "somewhat newer danger of denying its existence altogether", which he attributes to the effects of Quine's "Two Dogmas" (Quine 1951). ${ }^{6}$ Thus, Putnam should be seen as reworking 
the distinction into a tenable view. He was so successful that the resulting position remains one of the centerpieces of his philosophy. ${ }^{7}$ In view of the importance of the issue for understanding Putnam's epistemology, it deserves somewhat extended attention.

Putnam's discussion starts from a qualified endorsement of the holism expressed in the second, anti-verificationist and anti-reductionist argument of "Two Dogmas". The endorsement concerns Quine's metaphor that our system of knowledge is like a field of force within which there are multiple and changing justificatory dependencies between beliefs, and is combined with the idea of general revisibility. Putnam gives a special twist to this idea by splitting it up into three theses that present the system of knowledge not as a rigid, determinate unit but as a systematic, flexible and malleable whole (1962, pp. 40 ff.). The three theses are (1) the underdetermination of theory choice by experience: our beliefs face the tribunal of experience collectively and revision can come anywhere; (2) revisions are not merely local but may have more or less severe repercussions in the whole system, including changes in the meanings of fundamental terms and statements (this could be called systematicity of knowledge and belief ); (3) statements in our conceptual system fall on a continuum extending from clear analytic cases ("All vixens are foxes") to clear synthetic cases ("There is a red balloon over there").

These theses support an important consequence: if our beliefs lie on a continuum, and if revision can strike anywhere, and if the effects of revisions are not local, then the same belief may be located at some place on the continuum at a given time (say, be fairly analytic) but, as a consequence of some revision elsewhere in the system, find itself at a different place at some other time (say, become quite synthetic). Not only the truth-value, but also the epistemic status of a belief in a given system of beliefs is contingent on empirical knowledge, which means that the epistemic status of a given belief is determinate only relative to a fixed body of belief.

This consequence allows Putnam to account for the revisibility of framework principles, like those of geometry. To describe their special status, Putnam takes the inside view and puts the use and function of such beliefs on display in order to make the differences with typically "synthetic" beliefs visible. First and foremost, framework principles in Putnam's sense are "included in the body of knowledge" and "thought to be true by someone whose knowledge that body of knowledge is" (1962b, p. 240). From the point of view of justification, they are "employed as auxiliaries to make predictions in an overwhelming number of experiments, without themselves being jeopardized by any possible experimental results" (1962a, p. 48). Accordingly, 
"one is not expected to give much of a reason for that kind of statement" (1962b, p. 240) because, in the context of their being so employed, "the human mind [can] not conceive their falsity" (1965, p. 88). Moreover, Putnam claims that "holding them immune from revision... was good methodology" (1965, p. 92). Another important aspect of framework principles is their role with respect to the extralogical terms they contain. The concepts articulated in framework principles are fundamental and, like the primitives of geometry, "can only be defined in terms of each other", insofar as "the use of these notions rest[s] on a particular framework of assumptions" (1965, p. 89). Thus framework assumptions come in (use-structuring) systems.

For all that, framework assumptions are revisable, given suitable circumstances. In the case of Euclidean geometry, Putnam remarks, "a statement that was necessary relative to a body of knowledge later came to be declared false in science" (1962b, p. 241). However, "The revision of framework principles is (a) possible ... but (b) quite a different matter from the revision of an ordinary empirical generalization" $(1965$, p. 88). The special character of their revisibility-conditions accounts for the normative role of framework principles, while their actual revision is part of ordinary justificatory practices.

Putnam's general idea of how the statements in a framework that once were correctly held unrevisable can become the subject of evaluation and (with good reason) even be rejected as empirically false is that first the statements have to become synthetic, that is, change their status. Then they can be subjected to normal reasoning procedures for synthetic beliefs in general (and possibly be revised). Framework statements "can be overthrown only if someone incorporates principles incompatible with those statements in a successful conceptual system.... [They] are simply not abandoned in the face of experiment alone. They are abandoned because a rival theory is available" (1962a, p. 46).

Given Putnam's distinction between using experimental evidence and judging alternative conceptual systems, talk here of abandoning or overthrowing framework principles is exaggerated and, if taken as endorsing Kuhnian or Popperian epistemologies, perhaps misleading. In fact, since the status of framework principles is context-bound, what Putnam is suggesting is that, likewise, these principles are replaceable only if there actually is an adequate system in place allowing us to replace them. This suggestion leaves room to use statements of the older system within the limits and idealizations expressible by the new system, as when an architect uses Euclidean principles rather than factoring in the relativistic curvature of 
physical space (say, by requiring that his numbers be physically precise to the hundredth decimal place).

Putnam's main point is that the revision of framework principles is not an affair of canonical testing by empirical evidence, and this is what singles out those principles as enjoying a special status among our factual beliefs. Accordingly, the revision of framework principles requires alternative theoretical systems within which the candidates for revision can appear as empirical. Moreover, and in spite of not being subject (contextually) to ordinary empirical testing, if no alternative is in the field, framework principles subject to revision and used as extralogical premises in explanations and justifications - have to be regarded as factual. They are, as Putnam says, "empirical in the sense of being about the world" (1963a, p. 109). This latter point leads him to reject as well the conventionalist view of framework principles as "stipulations" and the instrumentalist view of them as a "mere systematization of the relations" (1963a, pp. 108 and 95) - both understood as opposed to factual statements. Putnam counters the reductionist tendency to consider framework principles nonfactual just because the justification of their revision is not reducible to simple empirical arguments. He objects that the assumption of the objectivity of framework principles is presupposed by their revisibility since, if they can be seen to be false, then they have to have been held to be true, and thus held to state facts. This argument uses the epistemological presumption of general revisibility and the semantic principle that a true (extralogical) sentence is held to state a fact. Framework principles in use are factual assumptions on a par with other empirical assertions of the system, and their adoption can be supported by reasons internal to the practice of empirical belief fixation.

This idea is manifest in Putnam's explanation of why framework principles could be called "synthetic". Even before they are revised they are not analytic, in the sense of being true in virtue of the meanings of the terms involved alone, because the function of framework principles is not merely linguistic, but tied to their having systematic import. Given the same evidence, whether we assume one set or another of framework principles can make a difference to the factual claims we are able to assert or infer, and the relations among the various members of a given set of framework principles will usually yield lawlike generalizations - that is, further synthetic statements. Framework principles are not analytic because they are factually consequential. By contrast, analytic statements in a body of knowledge are "unverifiable in any practical sense, unrefutable in any practical sense, ... true because they are accepted as true, and because this acceptance is quite arbitrary in the sense that the acceptance of the statements has no 
systematic consequences beyond, ... e.g. that of allowing us to use pairs of expressions interchangeably" (1962a, p. 69). Also, when Putnam says that framework principles are "'synthetic' to the extent that they are revisable in principle" (1962a, p. 59), this, taken together with his view on the revisibility conditions for framework principles, brings out an important aspect of "synthetic". That framework principles have the contextual status they have is connected to a significant fact, albeit a quite unempiricist and nonphysicalist one; namely, the historical and social fact that there are no adequate alternatives in the field. ${ }^{8}$ This is important epistemologically because part of the justification of framework principles consists in the evaluation of available alternatives. In such a judgment, alternative framework systems play an evidential role in determining the merits of the existing framework. Whether there actually exist such alternatives is a not matter of stipulation or convention, which is why the acceptance of framework principles is not arbitrary. But, since there may already be such alternatives, and ones better in context than the present system, the accepted framework principles are also not absolutely necessary. By emphasizing the actual existence of alternative systems ("specific doubt" again), Putnam's treatment here cuts a nice middle ground between conventionalism and general skepticism.

Putnam sums this up by saying, "I am suggesting that each of us has an empirical justification, in a good sense of the term, for accepting the explanatory scheme" in question $(1969$, p. 447). The anti-antirealist insights stemming from Putnam's pragmatic transformation of the apriori into a contextual notion for systems of belief obeying the continuum thesis (c) is that framework principles in the right conditions constitute genuine knowledge, that doubting them requires knowledge and the obtaining of adequate facts, and that their truth-value therefore does not depend only on the state of the doubter/knower and the system of beliefs.

In sum, Putnam's criticism of the analytic-synthetic dichotomy yields the following conclusions. Nonlogical framework principles, the empiricists' paradigmatic candidates for "true by convention" or "nonfactual" assumptions, are and must be capable of being treated as factual beliefs if they are to do the work they actually do in normal practices of belief fixation. This capacity does not derive from their having a certain place in an inferential or justificatory network, but from their being taken as either true or false. Framework principles constitute beliefs whose correctness is not entirely determined by the system of which they are a part. Being able to defend the correctness of framework principles is not only a matter of coherence, convenience, custom or other instrumental virtues but also a matter of empirical information obtained in the application of statements 
of the system at large. And finally, the same statement may play the role of an unquestioned assumption in one context, and that of an empirical claim in a different context. For nonlogical statements of the framework, this means that their factuality and correctness is not a consequence of having or lacking a certain epistemic status (e.g., being counted as synthetic) but is generally presupposed for their having any function in a body of knowledge at all. ${ }^{9}$

As we remarked at the outset, Putnam's leading idea is general revisibility in the context of our inductive practices of empirical belief fixation. The result of his reflection on revisibilty, as applied to framework principles, is that they do convey factual information and they are revisable precisely for that: for being capable of stating facts and of being mistaken, like every other factual belief we may have. Put differently, we can say that background statements, when taken for granted, are taken to be true and subject to ordinary referential semantics. Thus we arrive at referential principle (2) for framework assumptions: they state facts, and are taken as objectively true and revisable as long as they are in use.

In the next section, we review how Putnam makes a related case for empirical terms, with the result (3) that occurrences of the same term in different theoretical and background contexts can (given adequate conditions) be treated as co-referential; that is, be subjected to being evaluated with the apparatus of ordinary referential semantics as well.

\section{THEORY-CHANGE AND CONTINUITY OF REFERENCE}

Putnam's reflections on conceptual change concern our use of empirical concepts. He shows that taking them as referential - as referring to certain things and not others - cannot be understood in verificationist terms. Rather, he argues that the decision to take a term as referring to something and as referring to the same thing on two occurrences depends on the results of actually applying it to a local environment and on how we judge the sameness and difference of those results. In particular, Putnam's analysis of the use of terms in statements that are considered revisable takes issue with two views associated with verificationism, respectively, the criterial view and holistic conventionalism. Putnam addresses the work of Malcolm for the first (Putnam 1962c) and of Feyerabend for the second view (Putnam 1963a). On the first, criterial view, each concept " $F$ " is taken to be associated with a criterion or rule of language that determines when to say whether an arbitrary object is correctly called "F". On the second 
view, a whole network of beliefs or theory is used for the same purpose. On the first view, changing the criterion means changing the meaning of a term, on the second, changing the theory means changing the meanings of what we might call the theory's eigenterms. The main difference between the two views is that the first takes knowledge of the criteria to be a special sort of knowledge ("knowledge of meaning"), whereas the second takes the theories themselves to be largely empirical but requires a special type of justification for their acceptance ("convention", not confirmation). We look first at Putnam's response to the criterial view, and then quickly apply the lesson there to holistic conventionalism.

Putnam's counterstrategy is based on treating criteria as first and foremost part of a system of empirical statements (in fact, if they formulate at least sufficient conditions, they are to be considered as relying on laws), and on treating the use of general empirical terms as, broadly speaking, inductive. As empirical, the statements used in criteria can become subject to revision. The general idea is that criteria are descriptions of standardized situations in which the term in question can be taken to apply to an object or feature. When we (contextually or historically) change the criterion for a term but continue using it in a fact-stating practice, we no longer treat the criterial descriptions as marking relevant similarities that objects or features must meet in order to be considered as correctly described by the term specified. Nevertheless, the objects or features described by the criterion are still accessible to us after a change and are available as standard samples of the term in question (now regarded as merely indicated by the former criterion). The relevant similarities generated by the new criterion get anchored by finding that sufficiently many samples also satisfy the new or contextually more relevant measure to a satisfactory degree (i.e., within the contextually accepted margin of error). ${ }^{10}$

This idea is integrated into Putnam's picture of general revisibility by treating theoretical terms as "law-cluster terms" (1962a, p. 52 and 1963c, passim). This move sets the statements first used as "definitions" or criteria on a par with other statements containing the term. If, for example, the term "A" was introduced as denoting an object iff it satisfies the cluster $F$, $G, H$, and it is an empirical fact that such objects are always $L, M, N$, then it is an empirical fact that both descriptions are co-extensional under relevant initial conditions $X Y Z$ (and the relevant ceteris paribus clauses). Thus, if we need a description of some A's for whatever purpose, we have the choice to use either of the descriptions as long as the relevant conditions for applying them are fulfilled and everything is more or less normal. If we successfully use the second, "nondefinitional" description, this will, as a matter of fact, 
yield an object of which "A" is true. But then, in this context, it will be an empirical truth, if any, that the object determined by $L, M, N$ also shows $F, G$, $H$. Both descriptions simply switched their relative places on the continuum of epistemic statuses, and this is a consequence of a pragmatic attitude toward using alternative means for an end. Treating "A" as a different term just because it was applied under a different but extensionally equivalent description would be arbitrary in such a case. Once this is accepted, however, it is possible that, under initial conditions different from $X Y Z$, only $L, M$, $N$ are satisfied and $F, G, H$ either not applicable or false. This would mean that we find out that $F, G, H$ is false of some objects and events that satisfy $L$, $M, N$. The question whether to apply "A" in the latter case is clearly open (in the former, clearly unclear), and deciding it will depend on whether the phenomenon in question can be reasonably identified with other things already determined for " $\mathrm{A}$ ". Thus the empirical extension for " $\mathrm{A}$ " develops in inductive steps of judgment from application to application, judgments that involve normative attitudes and a lot of know-how acquired in the ongoing practice of inquiry. The extension is not simply determined by some one criterion given in advance. But in case we do decide to identify the results already obtained for "A" with this new case, it would be false that all A's are $F$, $G, H$, hence the statement initially used without restriction (as a "definition" of the class of all A's) would have been revised. Whether we do decide to view the revision of criteria as a change in empirical knowledge about the class of all phenomena denoted by " $\mathrm{A}$ " will usually depend on the historical and social situation. It depends on whether in practice we can reasonably defend lumping together the results of applying " $\mathrm{A}$ " as sufficiently similar; that is, it will be a question to be decided by scientific practice itself. Whatever way the decision goes, though, it will have been decided neither by one nor by the other criterion alone.

In view of the unforced character of the decisions involved, Putnam succinctly says "That criteria may be over-ridden when good sense demands is the sort of thing we may regard as a 'convention associated with discourse' ... rather than as something to be stipulated in connection with the individual words" $(1963 \mathrm{c}, 328)$. In cases of revision or override, the former criterion would nonetheless still be a useable way to access those elements of the extension of "A" of which it is true. Although it would not determine the extension of " $\mathrm{A}$ ", it would indicate some A's. Putnam puts this as follows: "with the development of new scientific theories it is constantly occurring that sentences that did not previously 'have a use' ... acquire a use - not because the words acquire new meanings, but because the old meanings as fixed by the core of stock uses determine a new use given the 
new context" (1960, p. 377). So the standard samples as determined in the old context are taken as candidates for the application of the new theory, satisfying (or not) the new descriptions in a contextually determinate way. ${ }^{11}$

Since any of the statements occurring in our system of empirical knowledge might turn out to be false (general revisibility), Putnam generalizes as follows: "our 'criteria' are good but not perfect indicators. The accepted criteria are often modified in the course of time... [and] the changes in the accepted criteria reflect the fact that we have more and more knowledge" (1962c, p. 311). Putnam takes it that investigators normally regard their ways of determining reference to be empirical and therefore inductive, revisable and fallible. Regarding those ways as an absolute warrant would mean not to let terms refer to anything that does not exactly obey given criteria, and to hold that the objects of reference are either captured correctly by those criteria or don't exist. The ascription of such absolute warrants, however, "does not do justice to [investigators'] probable intelligence.... . In all likelihood, they knew perfectly well that their criteria were crude ways of detecting what they were talking about" (1962c, p. 312). In an apt expression of Gary Ebbs (2001), criteria are cues to motivate a decision, but not general means to bring a decision about. ${ }^{12}$ Referential decisions are underdetermined by the successful application of criteria in a situation.

On the other hand, in cases where theories have undergone significant changes, we may have definite reason to worry about continuity in the use of concepts. If we have specific questions about the similarity of the results of their application to things we usually call "A", we may suspect that what is supposedly being referred to seems to have changed too much. Putnam illustrates this with the example of an (imagined) change from a criterion embodying an etiological pattern to diagnose multiple sclerosis to a virological criterion. "On [our] view the question of interest is ... what, if anything, answers to our notion of multiple sclerosis. When we know what answers to our criteria ...that - whatever it is - will be the 'extension' of 'multiple sclerosis" (1962c, p. 311). We need to examine whether Putnam's "that" stands outside the practice of inquiry. His redescriptions of the situation in terms of "natural kinds", "underlying conditions" and the like certainly suggest that it did. ${ }^{13}$ Perhaps we may need a finished theory of the universe in order to know what we are talking about and whether we are actually stating empirical facts when we take each other to do so. At least we appear to need a total extension that is fixed independently of use (as opposed to developing in use) in order to be able to state empirical truths. But do we?

According to Putnam's remark, the extension of "multiple sclerosis" is not determined by some one set of criteria in advance (or in the end), 
but is developed inductively from the referents that we contextually determine using this or that criterion. Perhaps we do so in an open-ended use of the term, as his account of the "acquisition of new senses" by the terms we use in an ongoing practice of inquiry indicates. Thus Putnam's picture of a contextually successful use of concepts that is open to changes in the associated criteria actually requires much less than a fixed extension for a practice-transcendent "that". As long as we do not "know what answers to our criteria", "the use of the term is based on the supposition that there is something... for which our 'criteria' are good but not perfect indicators" (1962c, p. 311). This is enough for a minimal commitment that is not anti-realist but also not (metaphysically) realist. That commitment denies the verificationist principle (more generally, the principle of semantic determinism) that epistemic application conditions and current theory taken together fix the reference of a given term, so that changes in the former entail changes in the latter. For Putnam, by contrast, our ordinary representational vocabulary and the fact that we take ourselves to be talking about the world cannot be explained away or overridden by epistemic substitutes. Questions about referential continuity are relevant to questions about conceptual continuity, not because they can be derived from theoretical or epistemic principles concerning continuity through change, but precisely because they cannot be. When we look at holistic conventionalism, which regards theories as criteria, in the sense of algorithms for the application of its eigenterms, the same argument applies mutatis mutandis. So it too fails.

Putnam buttresses these reflections on reference with a continuity rule: 'don't multiply references beyond necessity' for co-reference. ${ }^{14}$ This is not a methodological maxim for observers of the practice but a rule of thumb for participants who generally take the claims of others at face value. If our practice of applying referential semantics to others' discourse is to work, what we actually do in taking their claims at face value is best described as working on the assumption that they referred, and that, if they used the same word as we do, generally we can treat occurrences of it as co-referential with our word. This is (and should be) the standard attitude toward others' language use in a practice that allows for all sorts of revisions, including conceptual change. This rule is clearly nonepistemic in that our success in applying it is not derived from our estimate of the similarities of our and the others' specific beliefs concerning the denotation of the term, nor from anything else.

Putnam's continuity rule, as we said, is a rule of thumb for participants in certain practices, and it reflects a standard attitude. In virtue of the former, 
it is not unconditional, and in virtue of the latter, it does not issue in some "big truth" about our practice. It should not be overblown into a general maxim or global methodological requirement. It simply calls for there to be good reasons in specific and locally well-defined cases if we decide that occurrences of the same term are not to be treated as co-referential. Here are some of the implicit conditions of the application of the rule. (i) Users of a term assume that the statements they make in using the term are mutually relevant to the claims they are entitled to make, and that the change in beliefs associated with a term are reflective of a (self-correcting) learning process. (ii) Users of a term can rely on some continuity in the practice of theorizing; that is, the same term is used by both as representing a certain kind of quantity, magnitude, classifier, etc. (iii) Users of a term can make a case for (or at least give a good account of) redescribing the entities referred to by others such that each can consider the description as a reasonable extension of their use.

These conditions are trivially satisfied in the case of users of a term in more or less contiguous ongoing practices. In these conditions, the standard attitude appears to participants as the natural attitude. It results in our fully applying referential semantics to others' claims and holding them responsible on this basis. Nevertheless, if one or more of these conditions appears to fail, this may give us reason to revise our decision to apply the rule of thumb in this case. Such a revision could result in our not any longer unqualifiedly applying referential semantics to the others' statements, uses of a term or whole set of beliefs. ${ }^{15}$

The "realist" outcome of Putnam's arguments in this section can be summed up in the thesis that concepts may remain invariant across even radical changes in belief. If they do remain invariant, taking them to be so is an interpretative decision, that is, a pragmatic affair. What we normally take to be invariant in processes of empirical belief fixation is the factor relevant for the factual claims we can use the term for, that is, its reference. Taking the concepts to be so invariant enables us to perform the evaluative and epistemic practices constitutive of our taking some of our beliefs to constitute factual knowledge. As a consequence, neither the existence nor the properties of the objects of reference are entirely dependent on the epistemic conditions we use to regulate the employment of the terms used to refer to them. Neither referentiality nor factuality derives from epistemic sources alone.

This rather lengthy discussion of Putnam's writings between 1959 and 1965 has brought to light important connections between his fallibilism (the principle of general revisibility), his pragmatic perspective and his realism. 
Concerning the latter we have seen how Putnam's rejection of forms of verificationism leads to a sort of anti-antirealism that supports referential semantics as a central presupposition of public practices of inquiry. That referential apparatus involves the three referential principles we mentioned at the outset. (1) Normally, terms used descriptively in public practices of making and exchanging empirical claims refer. (2) Statements at all levels in a system of empirical knowledge state facts, and are taken as objectively true and revisable as long as they are in use. (3) Descriptively used terms can preserve reference over dramatic differences in theory and belief. Particularly for the last to work in a public practice of making and exchanging claims, there must be some shareable domain of things to which the terms apply so that we can see whether the results obtained are similar in relevant respects. Thus, Putnam's pragmatic fallibilism also presumes the environmental principle (4) that there is a publicly shared environment in which applications of terms and theories take place, the results of which underwrite the correctness or incorrectness of our claims. This doesn't mean that there must be some one uniquely specifiable domain of things for all contexts of making and exchanging claims, but that for each such context there has to be some assumption of shared objects. What is important for the success of mutual interpretation is the publicity of the objects under investigation, not the uniqueness of the way they are specified. Therefore, the assumption of publicly available objects of investigation does not depend on there being canonical ways of specifying the objects. Thus Putnam's pragmatic perspective in these early works includes what we could call a minimal realism in use.

Even if we accept the connection between general revisibility and referential semantics, however, we might be tempted to ask further whether that representational apparatus can be given independent justification and anchoring. The instability of science, the historical fact of the overthrow of successive theories, for example, might challenge our reliance on truth and reference for treating empirical claims. This sort of worry leads Putnam to his explanationist defense of a more substantive realism, to which we now turn. ${ }^{16}$

\section{ON NO MIRACLES AND (SOME) SCIENTIFIC REALISM}

Putnam's arguments in favor of scientific realism in the 1970s take the form of arguments against miracles. "The positive argument for realism is that it is the only philosophy that doesn't make the success of science a miracle. 
That [(1)] terms in mature scientific theories typically refer ..., that [(2)] the theories accepted in a mature science are typically approximately true, that $[(3)]$ the same term can refer to the same thing even when it occurs in different theories - these statements are viewed by the scientific realist not as necessary truths but as part of the only scientific explanation of the success of science" (1975d, p. 73). Thus Putnam begins to shape the referential principles (1)-(3) that underlie inquiry into a specifically realist doctrine that links practice with success and truth. As he says, "practice is primary; ... we judge the correctness of our ideas by applying them and seeing if they succeed" (1974a, pp. 268-269). ${ }^{17}$ If they are correct, they succeed, and the truth of our beliefs is the "contribution of linguistic behavior to the success of total behavior" that accounts for the reliability of certain forms of learning (1976a, pp. 102ff.). A second formulation of the argument comes from Meaning and the Moral Sciences (1978). Here, Putnam says that realism is "an over-arching empirical hypothesis" (p. 20) that explains two things: "scientists act as they do because they believe (1) and (2), and ... their strategy works because (1) and (2) are true" (p. 21). This pictures science (and learning in general) as an activity that issues in publicly assessable knowledge claims. It expresses the idea that only representational success explains empirical success, for otherwise the reliability of theory-laden methods of public assessment would remain a "miracle".

At the time Putnam called the referential principles (1)-(3) "internal realism" (1976b, p. 130), ${ }^{18}$ because he assumed, seemingly in line with the pragmatic perspective, that it constitutes "science's explanation of the success of science" (1992b, p. 352). But while it is correct that these assumptions correspond to what Putnam had taken to be presuppositions of the inductive practices of inquiry, we shall see that, from the outside perspective, where the practices of gaining empirical knowledge are treated as an object of study, they acquire an entirely different character.

To understand the catalytic role of these 'no miracles' reflections for Putnam's development more fully, it is useful to add another line of thought that, coupled with a certain picture, motivated his search for arguments in favor of realism. We saw that his endorsement of general revisibility and the contextual apriori entail the possibility that theoretical claims may turn out to be false and certain theoretical terms may come to be seen as nonreferential. But if scientific progress involved some sort of general representational failure, Putnam now argues, then the very "communicability of scientific results" and the practices of their public evaluation (1975c, p. 237) - in short the publicity of science - would become a miracle. ${ }^{19}$ However, claims whose correctness cannot be subjected to public scrutiny for lack of shared 
content can scarcely be regarded as objective in any interesting sense (or taken at face value). This gives rise to another explanationist strategy, the Peircean one of deriving the concept of an objective reality from the fact of failure itself (Peirce 1868). The central thought is that our capacity to recognize beliefs as fallible would be a miracle if their correctness depended only on internal factors, like thoughts, beliefs and will. Thus the only explanation for the failure of our beliefs, collectively, is that there is something outside thought, but connected with it, that is responsible for our beliefs' correctness. Now, identify the environment we apply our theories to with the external factor (the one that is "independent of our will"), and we are left with external reality (as opposed to, say, our collective system of beliefs) as the explanans. So casting familiar practices and their results as miracles goes right along with converting the local environments (the fourth, environmental principle) into a global "external reality". This step takes the open-ended, commonsense notion of an environment with which our instruments, theories and perceptions interact and replaces it with a theoretical concept that is supposed to capture the essence of the conditions of objective truth in general. It generates a picture of objective knowledge, later called by Putnam "metaphysical realism" (1981, p. 49). Apart from embracing the possibility that our best theories could fail to be objective (now in the sense of "not accurately reflecting reality"), it assumes that there is some fixed, uniquely structured world of theory-independent entities ("reality") to which all true theoretical statements must correspond. Theoretical terms from all theories are linked to these entities in a determinate way, and all theoretical change reflects changes in knowledge about this reality. This reality is, as it were, the deep-structure of the world in which we live. Since our theories reflect it pretty accurately, when we act on the basis of what our theories say, we are bound to be successful. We shall refer collectively to the no-miracles argument coupled with referential principles (1)-(3) plus the picture of an external reality that grounds judgments of objectivity as the explanationist defense of scientific realism.

Principles (1)-(3) have an ambiguous status in Putnam's philosophy at the time. On the one hand, without the realist picture, they seem to underwrite a quite natural account of the communicative basis of scientific inquiry as a public activity dealing with fallible factual claims. This basis consists, quite simply, in taking each other's claims at face value wherever reasonable and thus subjecting them to the norms of deductive and inductive inference, which in turn are essential to regarding others' empirical statements as evaluable in fallible practices of acceptance. One of Putnam's achievements was to show that the verificationist attempt to treat reference 
as determined from epistemic sources fails to do justice to many important features of this practice (underdetermination, general revisibility, antiabsolutism, etc.). But at the time of the explanationist defense Putnam was tempted to go beyond the pragmatic treatment of objectivity that emerges from the presupposition of general revisibility. The picture added to the three referential principles tries to go further by holding that what really accounts for the correctness of our claims is a definite way the world is. Thus the role of the realist picture is to distinguish between beliefs that are objectively right and those that are merely intersubjectively acceptable.

However, the referential principles that we need to invoke if we take each other at face value and as subject to the norms of fallible inquiry run into well-known problems when they become entangled with the realist picture and the denial of verificationism. The classical difficulty is the coupling of independence, externality and connectedness that issues in a problem of access. If we take a given theoretical statement and, in the pursuit of our aims, want to know whether it corresponds to reality, we need access to the "real" state of affairs. But if the state of affairs is independent of beliefs or cognition, we fall into a regress, since with respect to whatever cognition we use to gain access, we will need to know that it too corresponds with reality. Similarly, if we demand that the truly objective entities our terms refer to are independent of all cognition and we want to determine the referent of a particular term, we will need cognitive contact with it, which means that we take the referent, not as independent, but as observed or as described. ${ }^{20}$ As Putnam frequently stressed, the referential principles cannot tell us how to establish referential connections but presuppose them. ${ }^{21}$ The problem of access turns precisely on the question of how to have this presupposition in the picture. So, if our cognitive access to reality is neither immediate nor guaranteed (e.g., by epistemic criteria), and reference and truth consist in a determinate correspondence to mind-independent reality (to which we don't have such access), then we seem incapable of providing reasons for the belief that our terms refer or that our statements are true in this correspondence sense.

This presents us with the following situation. The referential principles alone account for the public and communicative character of scientific practice, without either verificationism or the realist picture. The role of the realist picture was to explain the objective revisibility (and independent confirmability) of the factual beliefs dealt with in these practices. But the picture, by opening up the problem of access, blocks any defense of the referential principles that depends on direct access to the referents of our terms. Thus, accepting the picture to explain the objectivity of our 
claims actually weakens our prima facie reasons to believe in the referential principles. However, if we were to abstain from assuming those principles, we would cease to regard our claims as referring and being true (or false), and then we could hardly regard ourselves as engaged in "discourse" at all. Similarly, without the realist picture, our "discourse", it seems, would be merely a socially shared activity, but not an objectively evaluable practice concerned with empirical knowledge. It thus comes to seem that we need to restore our confidence in the referential principles with the realist picture. In that case, however, we need a line of argument that avoids any form of immediate access. Putnam's flirtation with the explanationist defense can be seen as just such an attempt to find an indirect argument for the referential principles with the realist picture. ${ }^{22}$ Does it work, or even, could it work?

\section{WHY THE EXPLANATIONIST DEFENSE DOESN'T WORK}

The expression "success of science" is ambiguous. It could mean the (instrumental, predictive, empirical) success of scientific theories - which is what the referential principles are about - or it could mean the success (e.g., reliability) of scientific methods in producing empirically correct statements. With respect to both, we can have prima facie doubts about the actual threat of miracles (and the corresponding comfort of explanations).

Seen from the pragmatic perspective of reasons that bring us to accept a theory, the very idea of an explanation of the "success of science" in the first sense seems puzzling. ${ }^{23}$ Of course, acceptance is underdetermined by evidence, and theories can be accepted but turn out to be false. But when we accept a theory as true, the most compelling reason is that the theory is successful, and when we accept an alternative, one of the reasons why it is in the field as a serious candidate is that it is at least as successful as the theory to be replaced. Both in the process of acceptance and in the process of revision, success is a condition rather than a result of taking theories to be true. Our practice of theory acceptance, in requiring success as an entitlement, pragmatically excludes that we might take an unsuccessful theory to be true. But then the best explanation of the success of theories in mature sciences is that these are just the theories we admit. ${ }^{24}$ In this sense of "success" there is nothing in the success of our theories that requires explanation. However, this also seems to extend to a defense of the strength of methods. For we often take the procedures of empirical sciences as our standard, so our practice entails that we expect the methods of science to be more successful than other methods. ${ }^{25}$ But then it is pragmatically incoherent to 
ask for an explanation of the success of science as if the latter were not to be expected ("a miracle").

One might respond, as Putnam (1981, p. 39) does to van Fraassen, that we could not require success for theories or methods if they could not have it (or only happened to have it). Realists would add that only theories which correspond to a mind-independent reality succeed, and the others don't. At this point the realist moves outside the normative participant's perspective to what Putnam calls the "God's Eye point of view" and insists that we take up the "challenge" of explaining success. At the same time, the realist tries to stand inside our practices in order to take scientific successes seriously. These retrograde motions entangle the explanationist defense in problems that run deep. ${ }^{26}$

First, the problem of access returns with a vengeance when we compare ordinary explanatory practices in science and the explanationist defense. Among the requirements on explanatory, empirical hypotheses is that, in principle, they be independently testable and that they generalize. This prevents a hypothesis from being just a shortcut for summarizing some particular experiment or pattern of observations, and thus is crucial for our treating the proposed hypothesis as factual. In terms of Putnam's early philosophy of science, a factual element requires that the parameters in question be part of a law cluster, a system or structure of law-like connections that work in sufficiently independent ways to be mutually confirmable. In view of this, the content of the explanationist defense is peculiar. Since the defense encompasses all reality and every theory that is to have any empirically ascertainable content, it follows there is nothing left for it to generalize to. Moreover, whatever access we propose to the parameters in question (to "reference", "reality", etc.), depends on using our referential principles along with the realist picture of a mind-independent world. But then, according to the usual standards, the explanationist defense is not a proper explanatory, empirical hypothesis after all. The explanans does not generalize and it cannot count as factual insofar as it employs parameters that are not accessible without assuming that very hypothesis; that is, it is not independently testable. Indeed, the explanationist defense seems trapped in a vicious circularity.

But perhaps that is unfair. Precisely since the explanationist defense ranges over all science and takes all of science as its evidential base it needs to cover only one big situation. What else should it generalize to? So, it cannot have been intended to be empirical or scientific in the sense of confirmable. Perhaps when supplemented with the realist picture the referential principles are framework assumptions - very general, unstated, unproblematic 
but needed as background. Then, as Putnam so convincingly argued in his early writings, they would indeed be factual. However, there are (at least) two reasons why they cannot count as framework principles. One is obvious: they fail the test of not needing reasons, since the explanationist defense is offered as just such a reason! The second is that there are viable alternatives, and so they fail the test of being required as auxiliaries in our empirical justifications.

As to the second, it is clear that the fact (if it is one) that our theories are true and their terms refer does not make them successful at any task, unless "success" is defined as representational success. But then the defense is obviously circular, as then the truth and reference of our theories explains the truth and reference of our theories (their representational "success"); hence Putnam's insistence on practice rather than representation as primary, and his emphasis that the successes in question involve application of theories to empirical circumstances and observing whether the results are, relative to the expectations warranted by the theory, positive or negative. But this clarification of the explanandum gives rise to a perfect symmetry between realism and a form of antirealism, namely instrumentalism. ${ }^{27}$ As Putnam later recognized: "when we try to make the vague claims of the metaphysical realist precise, we find that they become compatible with strong forms of antirealism" (1992b, p. 353). In our context, this can be seen as follows. Suppose "success" involves applying a theory to certain empirical circumstances and observing whether the results accord with the theory. Then, if we have positive results, this warrants saying that in the given circumstances (under the assumed interpretation) our theory was reliable. Thus the hypothesis that our theory is reliable in general explains why, under these particular circumstances, we were successful. By contrast, the realist would say that our theory's correspondence with reality explains its success because the mechanisms described by the theory work as the theory says and, if they do, the observed result must obtain. Now, in all cases where the realist can invoke this explanation in terms of correspondence to reality namely, the cases where the theory actually does explain the result of an application - the instrumentalist can invoke his explanation of the result in terms of the general reliability of the theory. Actually, we find that wherever there is some specific success and a satisfactory explanation based on the realist picture, we can reinterpret "truth" in an instrumentalist manner, and the result is an explanation that is perfectly acceptable from an instrumentalist point of view. ${ }^{28}$ But then it is false that realism is the only, or, in view of the symmetry, even the best explanation of success. In any event, the realist suggestion that, because they have no alternative, the referential principles, 
when combined with the realist picture, are framework principles does not work.

\section{WHY THE EXPLANATIONIST DEFENSE COULDN'T WORK}

This brings us to a second reason against regarding the realist picture as necessary in scientific reasoning. These considerations will bring us in contact with Putnam's more recent work, as this last effort to revive the explanationist defense forces us back to the participant's perspective, and thus backfires on the realist. How could a semantic picture help us understand the success of scientific practice, a historically situated and practical process? ${ }^{29}$ Whatever is responsible for particular scientific success is not some semantic property of our theories but a feature of the environment in which they have been employed. For example, the bridge holds up because it is statically sound, not because of the truth of our theory describing the bridge as statically sound. Likewise, no additional account of truth or reference is needed to explain the success of scientific activities insofar as they are explicable at all. From the perspective of our explanatory use of theories, truth adds no more than disquotation; ${ }^{30}$ the statement in our theory "the bridge is sound" is (empirically) true iff (in fact) the bridge is sound. In general we can say that wherever scientific practice results in a good explanation for some given success, the explanation does not get better (simpler, more acceptable, more cogent) by adding the referential principles and the realist picture.

This argument might be seen as question begging insofar as it supposes that semantic reasons are nonsubstantive, and therefore are the wrong kind of reason (aren't we smuggling in an analytic-synthetic distinction?). But this charge overlooks the scope of the explanationist defense. Scientific (first-level) reasons provide local and specific grounds for holding a certain belief. The explanationist defense works globally, supposedly applicable to all scientific reasoning, and unspecifically. (In parallel with Peirce's famous "paper-doubts", one could call it a "paper-reason".) Once we take specific instances, for example, by saying that some particular theoretical statements refer (are true, correspond to mind-independent reality) and we "disquote" (i.e., read the statements as making factual claims), then we are simply adding some empirical data (the theory's laws and its results) to our explanation of a certain success. None of these statements speaks of mindindependent reality as such, while each of them, if accepted as true, is taken to state an empirical fact. When actually used in the explanation of given 
successes, the specific instances of the explanationist defense result in ordinary, empirical explanations. So, taken globally, the referential principles with the realist picture do not add explanatory power to science, and when taken in specific instances, the principles simply convert specific theoretical and observational statements into factual claims. The realist picture drops out, and we have a more or less reliable ordinary, first-order explanation involving "just more data".

With Putnam, we conclude that the metaphysical realism of the explanationist defense is not needed for an explanation of any empirical successes of science. In its explanatory work, science takes care of itself. This rules metaphysical realism out as part of the framework principles presupposed in scientific explanation. Thus the three referential principles need not be understood in terms of a mind-independent reality and our relation to it. In view of this, we conclude that the explanationist defense of scientific (or metaphysical) realism is a failure.

Earlier we noted that, under the assumptions of metaphysical realism, the problem of access stands in the way of any direct reason to believe that our claims have the referential features they seem to have when we use them to state facts. Therefore, it seemed, we needed an indirect reason under that assumption. Now we see that the most promising indirect reason fails. In this situation, there are three obvious moves: $(a)$ rejecting the referential principles, $(b)$ rejecting the realist picture, or $(c)$ rejecting anti-verificationism. Putnam's early pragmatism allots a central role to the referential principles (without the realist picture) in our public practices of making and exchanging factual claims. For him, our use of these principles simply embodies the communicative attitude of taking each other's claims at face value, and that means if we take them as true, then we take them as stating facts. This was part of his motivation to look for an indirect argument instead of just resigning before the problem of access. So, (a) is not a plausible option given Putnam's pragmatic outlook. The fact that our attempts to ground the picture of a mind-independent reality have forced us out of the "God's Eye point of view" back into the perspective of our practices already indicates that the realist picture lacks coherence. That impression deepens once we realize that instrumental success in science involves interacting with the environment just as much as reference through indication does. Moreover, if success counts as relevant to our knowledge (confirmation, information, etc.), then success is as much a cognitive way of accessing the world as reference. Thus, the problem of access begins to look like a red herring. This will be the starting point of Putnam's recovery of our ordinary notions of representation and reality. He will also find 
independent reasons that seriously undermine the realist picture, so it is fair to say that the failure of the explanationist defense leads him to that recovery. Nevertheless, for quite a while, Putnam combined (b) and (c), and steered what he called a "moderately verificationist course" by identifying truth with warranted assertibility under epistemically ideal conditions. ${ }^{31}$ He has frequently stressed that he considers this attempt as flawed and now rejects this conception of truth (1994d, pp. 242ff. and 1992b). At one point, he even portrays his former self as "simply past[ing] together elements of early modern realism and elements of the idealist picture" (1999, p. 18). The suggestion is that, in spite of having independent reasons against the picture of a mind-independent but fixed and unique reality, he was still worrying about the problem of access - the one verificationism is geared to - posed by the very picture in which he had no more deep faith (1999, pp. 3-20).

Once this flirtation was over, however, Putnam jettisoned the realist picture, remarking that "the attempts at clear formulation never succeed in capturing the content of 'metaphysical realism' because there is no real content there to be captured" (1992b, p. 353). At the same time, Putnam preserves a version of the referential principles for our fallible practices involving empirical claims, just as he had characterized them in his earlier writings. Putnam's current work aims at providing a better understanding of those principles as natural assumptions, neither explanatory nor problematic, and thus not in need of any special assurance or license for their use. Developing this position is what he calls "rejecting 'realism' [read: the realist picture] in the realistic spirit" (1990a, p. 42) by "the recovery of our ordinary notion of representation (and of a world of things represented)" (1994b, p. 300). It moves from miracles to a reality beyond miracles, our practices themselves. The explanationist defense of realism withers away, as do the miracles, and something better results from the interaction between the pragmatic outlook Putnam had developed in his early work and his fling with realist metaphysics. (This is why we called his reflections on the defense "catalytic".) Putnam's considered position is thus aptly called "pragmatic realism".

\section{PRAGMATIC REALISM}

In his more recent work, Putnam has begun to reflect on the pragmatic perspective of his early work and on pragmatism itself. Thus we see a number of articles dedicated to the study of philosophers in the pragmatist tradition, 
and above all to the work of the later Wittgenstein. Moreover, Putnam's interest in these studies is not merely exegetical but systematic, as becomes most apparent in his (1995). We would like to close this essay with a perspective on some of the elements of Putnam's current, complex view. That view presents us with a multifaceted dissolution of the metaphysical realist picture and its attraction, while at the same time preserving the commonsense realism that participants rely on when they regard the claims they make as fallible. Putnam characterizes this program as follows: "preserving commonsense realism while avoiding the absurdities and antinomies of metaphysical realism . . . is something I call pragmatic realism . . . it is a view that takes our familiar commonsense scheme, as well as our scientific ... and other schemes at face value" $(1987$, p. 17). Thus Putnam's reaction to the failure is not to give up the referential principles (1)-(3) but to revert to the participant's perspective and from there to deepen his reflection on their use in our practices of evaluating empirical claims. In the course of this reflection he dismantles the metaphysical realist picture and recovers the environmental principle (4), the commonsense idea of a publicly shared environment, as its pragmatic counterpart. We shall approach Putnam's current position by discussing its central elements, the first of which is the participant perspective.

The first conclusion Putnam draws from the failure of the explanationist defense is to insist that questions about the objectivity of our knowledgeclaims can be discussed usefully only from the perspective of participants in ongoing practices of belief-fixation, because the results reached there are the only paradigms of empirical knowledge that we have. "The heart of pragmatism, it seems to me... was the insistence of the supremacy of the agent point of view. If we find that we must take a certain point of view, use a certain 'conceptual system' ... then we must not simultaneously advance the claim that it is not really 'the way things are in themselves'" (1987, p. 70). The central point of Putnam's subsequent arguments is to show that this decision to abjure the God's Eye point of view is not equivalent to abjuring claims to objectivity, but rather shows the opposite. It shows that the picture of objectivity the metaphysical and scientific realists wanted to see our practices aiming at is neither operative nor needed, given the normative resources used in inquiry. This brings us to a second element of Putnam's current position, access and the independence of word and object.

From the perspective of practices in which we use a language to make and evaluate empirical statements, we find that there is no other access to whatever we can come to regard as real than through making statements and taking them to be, if true, then descriptions of reality. Putnam puts the 
point as follows: "Given a language, we can describe the 'facts' that make the sentences of that language true in a 'trivial' way - using the sentences of that very language" (1987, p. 40). Thus, from the standpoint of the practices of empirical inquiry, there simply is no global problem of access. When we come to take a statement to be true, we succeed in stating a fact. Putnam provokes the metaphysical realist by saying just this: "There are 'external facts', and we can say what they are" (1987, p. 33). When Putnam complements this statement by reaffirming the participant's perspective in saying, "what we cannot say - because it makes no sense - is what the facts are independent of all conceptual choices" (1987, p. 33), he points to a fresh approach to the problem of access. From the fact that we approach the world by making (true/false) statements it certainly does not follow that we have (can have) no access to it. Rather, we should conclude the opposite, that we access any "reality" that can play a role in helping us to determine whether a given statement is correct. From the perspective of participants who use language to make and evaluate empirical statements, the apparently astonishing claim that we have no access to "unconceptualized" reality is a triviality, for it "does not mean that reality is hidden or noumenal; it simply means that you can't describe the world without describing it" (1992a, p. 123$).{ }^{32}$

From this perspective, the metaphysical realist picture defended in the explanationist defense, the view that our claims have to "correspond to mind-independent reality" in order to be objectively evaluable, arises from conflating the "(platitudinous) idea that language can represent something which is itself outside of language" (1994b, p. 300) with the epistemological concern that in order to be justified in applying ordinary referential semantics, we have to be certain that there is something in the world that is connected (in the right way) to the descriptions we use. But the epistemological concern disappears when we realize, for example, that "according to our descriptions themselves, the word 'quark' is one thing, and a quark is quite a different thing" (1992a, p. 123). This difference is not between the "undescribed" or "neutrally accessible" on the one side and the "contaminated" on the other. Because we know how both the word and the object reached by disquotation can be described, there is usually no reason to believe that the respective entities (word and object) are necessary for either the existence or the specific properties of each another. According to our practices themselves, just as facts about spelling are not relevant to facts about quarks, in general, the fact described by using a certain linguistic expression in assertoric discourse and the fact of using this expression are, as Putnam says, "independent" in any sense we can understand, without 
involving anything "outside" the describable (1994b, p. 301). ${ }^{33}$ This brings us to a third element, referential semantics and standards of fallible inquiry.

According to Putnam's current view, applying referential semantics to beliefs that can claim to be objective is not a case of backing up our claims with a sort of guarantee. Rather, when we apply ordinary referential semantics to a class of statements, we regard them as having truth-values that do not depend on the mere fact of our acceptance, but on the result of a fallible evaluation (1992a, p. 77). Thus, "to say that truth is objective ... is just to say that it is a property of truth that whether a sentence is true is logically independent of whether the majority of the members of the culture believe it to be true.... this is ... simply a feature of our notion of truth" (1988, p. 109). So the problem of objective knowledge is the local problem of determining the truth-value of statements used to make empirical claims. The problem is not about comparing statements with reality as such (whatever that is). The problem is just that we do not know in advance, or by the mere fact that a statement is used on a certain occasion, or by the fact of just accepting the sentence, which of the two possibilities (true or false) is the case. But if one of a pair of contrary statements is taken to be true, its contrary cannot be simultaneously true. This means that in a language to which we apply referential semantics, for every answerable question there is just one right answer in the language. The metaphysical realist picture conflates this with the idea that there is a single descriptive basis that yields right answers for all answerable questions.

Choosing a particular way of describing a situation may amount to a "convention" or a matter of expedience, since it is not determined by the norms of referential semantics itself; still, this sense of convention "is not the view that, in some inconceivable way, it's all just language" (1987, p. 36), because when we want to know whether a given empirical statement (as opposed to its contrary) is to be taken as true, "the answer does not thereby become a matter of convention" (1987, p. 33). It is not a matter of convention because inquiry is inductive and open-ended. Recall Putnam's pragmatic criticism of the criterial or conventionalist ploys with respect to the semantics of empirical terms. From our perspective as participants in fallible practices of evaluation, talk about the "independence" of the world just amounts to the idea that the result of evaluating a certain statement in a situation is not (or rather, must not normally be) determined by consensus or convention. Rather, making a decision as to truth or falsity involves using referential semantics in a publicly shared environment in view of all the knowledge we can bring to bear on the question. With regard to this 
sort of decision, Putnam's work involves an increasing generalization of his earlier rejection of criterial views, resulting in his rejection of "algorithmic" pictures of the procedures of application in favor of the view that every evaluation in context involves "general intelligence" rather than specific knowledge of assertability-codes (1988, p. 75). ${ }^{34}$ What enters into the determination of the truth-value of a given statement can vary enormously from context to context, and always involves trade-offs and judgments of reasonability. Consequently, what is meant by "independence" is not some unique characteristic running through all those cases of settling on a truthvalue. In this approach to objectivity, using ordinary referential semantics (with disquotation) is, as Putnam succinctly remarks, "necessary for logical reasons, not for descriptive reasons" (2001a, p. 11). He explains this by the observation that "If ... statements are ... fully governed by norms of truth and validity ... [then they are, $\mathrm{AM} / \mathrm{AF}$ ] subject to the standards of fallible inquiry" (2001b, IV, 2). Thus, Putnam recovers the referential principles (1)-(3) from a thorough examination of the requirements of our fallible procedures of inquiry by way of deflation: they are not descriptive but normative. Still, we need to understand how Putnam integrates deflationism (cf. 1999, pp. 52-59; 2001b, IV; and 2001a, pp. 9-14) into his pragmatic epistemology. This will bring us to his combination of contextual evaluation and general revisibility.

The task is set when Putnam says "deflationism about truth - as long as it involves ... a verificationist account of understanding - adopts the most disastrous feature of the antirealist view.... What is wrong in [this kind of, $\mathrm{AM} / \mathrm{AF}$ ] deflationism is that it cannot properly accommodate the truism that certain claims about the world are (not merely assertable or verifiable but) true" (1999, pp. 55-56). Putnam has in mind contextually unproblematic statements like "there is a table in front of me" when uttered or thought while putting down one's cup. This might suggest that Putnam is reintroducing a substantive notion of truth, ${ }^{35}$ one where ordinary language provides the version of the world as it "really is".

We think not, however; rather we think Putnam is making a methodological point. In contexts where truth is at issue we take various statements as factual. This means we take them as true, although capable of being false. "The fundamental features of our cognitive situation (are): that we are fallible (knowledge claims are defeasible), and that we have the right to claim to know, in certain situations, at certain times, and for certain purposes.... Without genuine knowledge claims, there is nothing to be fallibilistic about" (1998, pp. 254 and 262). Such unproblematic, contextual judgments often reoccur in several contexts (cf. Fine's "local judgments of truth" 
[1996a]). Indeed, because of their familiarity (as opposed to their "thinness"), they work much like contextually a priori statements and, as a moving part of reasoned judgment, are essential to taking any claim as true (Putnam 2002, pp. 17ff.). Consequently, if statements evaluated with their help are to be objective, we must regard these contextual judgments themselves as capable of objectivity (not merely assertability). But this does not make them true substantively (describing how it "really is"). As with the contextually apriori, as context shifts they can be revised (without change of meaning) and thus lend themselves to neither a substantive nor a verificationist reading.

This treatment of objectivity supplements the principle of revisibility with a principle of contextual evaluation according to which evaluations of truth are always made in a context of specific reasons and conditions. A corollary is that one cannot divide statements into "unproblematic" or "problematic" independently of context. Of course, this does not mean that we cannot (or need not) make the contextual distinctions required for reasoned evaluations (cf. 2002, p. 22). Putnam's pragmatic epistemology thus embodies two general norms governing objectivity. First, every evaluation involves commitment to judgments of reasonableness that involve distinctions between unproblematic and problematic statements for the case at hand. Second, the result of an evaluation is expressed in terms of truth and falsity, or related oppositions of (objective) correctness. Thus the semantic categories and the contextual allocation of status are neither descriptive, nor gratuitous, nor reducible, nor substantive. Rather, Putnam regards them as methodologically normative with respect to objectivity. This brings us to commonsense realism, pluralism and the environment.

That this picture of objectivity and inquiry from the participant's perspective is not only satisfied by one but many descriptions is the basis of Putnam's pluralistic "commonsense realism". It starts from observations like "we may partly describe the contents of a room by saying that there is a chair in front of a desk, and partly describe the contents of the same room by saying that there are particles and fields of certain kinds present" (1994d, p. 243). At another place, Putnam says more generally that "the same situation, in a perfectly commonsensical sense of 'the same situation', can be described as involving entirely different numbers and kinds of objects" (1992a, p 120). It is important to see that the notion of the same room, the same situation or same state of affairs Putnam uses does not reimport the problem of direct access to a reality that wears its identity for users of various ways of describing it, as it were, on its sleeve, an unproblematic "given". Seeing how, though, is a delicate matter, and it involves us in 
another round of reflection. What is at issue is the recovery of (4), a publicly shared environment, without identifying it with "unconceptualized", "mind-independent" or "external" reality.

The idea underlying Putnam's view is the notion of a publicly shared environment as the normal domain in which evaluations of truth take place. He starts from the premise that we are "creature[s] with a certain kind of normal environment, and with a certain history of individual and species interaction with this environment" (1994c, p. 289). While this could still invite the impression that we are dealing with a given, that impression fades when we consider Putnam's pluralism and his deflationist way with the global problem of access. Recall that the problem of access for two descriptions that are used simultaneously in a situation is solved by disquotation, and thus each of the users of a description has access to the situation. The question then becomes what is involved when we regard the situation as shared. Concerning this Putnam says, "access to a common reality does not require incorrigibility ... [and] access to a common reality does not require access to something pre-conceptual. It requires, rather, that we be able to form shared concepts" (1995, p. 21).

This is somewhat enigmatic, but we can try to make it clearer by expanding on the possibilities Putnam indicates. We take him to say that sharing the situation does not depend on assuming either that we share a "neutral" description we agree on (e.g., "as it really is") or that we have direct access to the fact that the situation is shared. When Putnam speaks of our forming shared concepts, we take him to be employing his noncriterial view of concepts. This suggests that the publicity of the situation among users of different descriptions can be seen as the result of the same interpretative skills and practices that are at work in our use of inductive concepts as they are exhibited within each of the different descriptive practices. They "form shared concepts" by finding a way of approximating the extensions of the other description in extensions of their own, and by finding that, once this is done, the respective inductive developments of these extensions harmonize in sufficiently good measure in this type of context. ${ }^{36}$ What is required for this possibility is that there be a sufficient covariance in truth-judgments by each of the users of the different descriptions in what each of them regards (in their own ways) as the same sort of situation as the ones described by the (respectively) same statement on other occasions. In this light, Putnam's pluralism is committed to the view that "all situations have many different correct descriptions, and that even descriptions that, taken holistically, convey the same information may differ in what they take to be 'objects"' (1994b, p. 304). Thus someone describing the contents of a room 
in terms of chairs and someone describing it in terms of clouds of fermions can "share the concept" by taking the description of the room as containing three chairs to indicate the situation consisting of such-and-such clouds of fermions, and vice versa. ${ }^{37}$ One needs to be careful here, however, because the mutual reinterpretability of the descriptions in question does not imply that both descriptions are pragmatically equivalent through all contexts of application. If I want to know where my son has put the chair, I will not (in fact, must not) call up Fermi-Lab to find it; and if I want to know whether what is in the cup is coffee or muddy water, a redescription in terms of " $\mathrm{H}_{2} \mathrm{O}$, give and take some impurities" won't help me solve my problem. Still, this is compatible with saying that, if there is a beverage in the cup at all, then the chemical description will not say that, in fact, there is nothing or that there is a piece of platinum. Recall that the question was not how to produce good overall translations, but to find out whether Putnam's presupposition of a shared environment smuggles in the metaphysical realist's picture. If our reading is correct, it does not. What is required for "sharing" a situation and considering it as shared is the elaboration of an overlap in respective partial extensions (of the respective correlated concept-signs) as applied to the environment (as parsed by each version into their relevant parameters). It does not rely on shared descriptions. Since the partial extensions are accessible, in ordinary inductive ways, to the users of either description, there is also no supposition of direct access. Finally, since in case the correlated descriptions disagree this can produce a revision of one of the descriptions by way of the other, Putnam's view requires no incorrigibility. Thus access to a situation as shared is not through neutrality or direct intuition, but through common inductive practices involving communication and cooperation. To this effect, Putnam cites Dewey by saying that "the whole interaction is cognitive" (1994c, p. 289).

After his deflationary recovery of the three referential principles, Putnam can thus claim to have reclaimed the fourth, the presupposition of a publicly shared environment, from its identification with the mindindependent, external reality in the metaphysical realist picture. Instead of being "unconceptualized", the environment contributing to the determinacy of our evaluations of empirical statements appears as richly conceptualized and multiply accessible, but not predetermined by our evaluative practices. This brings us to the final element in Putnam's current view that we want to feature: ontological anti-reductionism and conceptual relativity.

The last step in Putnam's deepened reflection concerns the ontological idea contained in the metaphysical realist picture of a uniquely structured domain as the basis of the objectivity of our claims. In order to address 
this question, he draws ontological conclusions from the views developed so far (commonsense realism, pluralism and objectivity). They imply that the several descriptions that may be applicable in a particular case, while perhaps ordered into better and worse when it comes to answering different questions, are on a par with respect to objectivity. Each of them can be taken at face value, as stating facts if taken to be true. Putnam accordingly regards his pluralist, commonsense realism as "a view that takes our familiar commonsense scheme, as well as our scientific... and other schemes at face value" (1987, p. 17). At the same time, via disquotation, each makes different ontological assumptions that we, if we take them at face value, accept as a matter of course. This has two related consequences. The first consequence is that, in each such case of multiple describability, we have a choice of an acceptable way of describing the situation that is not dictated by the situations themselves. This amounts to choosing a set of ontological categories for organizing the situation. Putnam consequently says (with Kant and Goodman), "It is we who divide up 'the world' - that is the events, states of affairs, and physical, social, etc., systems that we talk about - into 'object', 'properties', and 'relations', and we do this in a variety of ways" (1994d, p. 243).

The full ontological force of Putnam's pluralism comes to light in view of the anti-reductionist conclusion he draws from applying referential semantics to multiple descriptions each of which has an equal title to objectivity. Given such multiple descriptions, the objects, properties and relations taken for granted in each are as real as the objects, properties and relations taken for granted in the others. Thus, "the statement that there are electrons flowing through a wire may be as objectively true as the statement that there is a chair in this room or as the statement that I have a headache. Electrons exist in every sense in which chairs (or sensations) exist.... Here I am a 'scientific realist'" (1982a, p. 495). In other words, "commonsense tables and chairs and sensations and electrons are equally real" (1987, p. 12).

Putnam is now in a position to subvert the heart of the metaphysical realist picture itself: the idea that our standards of objectivity presuppose the notion of a fixed, uniquely structured reality. The argument takes as given that we do use various contextually equivalent ways of describing the world to make empirical statements. We evaluate them according to the logical norms of referential semantics and the epistemological standards of a fallible methodology. Since the descriptions are not ontologically equivalent, the only way in which the ontological component of the metaphysical realist picture can be understood is as the epistemological thesis that there is one among the descriptions that is the best in all contexts. That unique one 
would then serve as a reduction base for deciding the truth-values of any of our empirical statements. Putnam has a number of arguments against this epistemological thesis, one of the most effective of which is his "companions in the guilt" argument (1982b; 1990a, pp. 135-142; 2002, p. 23). Roughly, suppose one disqualifies all claims that are not reducible to fundamental science as "subjective". This would likewise affect the normative notions at work in scientific methodology itself, and thus make scientific practice itself "subjective". But this is a reductio of the view that objectivity is grounded in an epistemologically unique basis.

Putnam's treatment of conceptual relativity is designed to show the same reductio. Here he focuses on cases whose structure inverts that of the cases used in his pluralist arguments. The general structure relevant to conceptual relativity is that "There are ways of describing what are (in some way) the 'same facts', which are (in some way) 'equivalent' but also (in some way) 'incompatible'" (1987, p. 29). The example Putnam often uses is where three individuals of some sort (say, particles) can be redescribed in a way that counts not only individuals but also all nonrepetitive combinations of these as "objects" (i.e., it counts "mereological sums"). In every situation in which objects are grouped according to one of the versions and counted, there is a correlate in the other version. If one of the versions is applied to a situation, say the initial one, and yields a clear result (" 3 "), then the other version yields an equally clear result ("7"). (In general, if there are $n$ objects in the first version, then there are $\left(2^{n}-1\right)$ objects in the second.) In each version there is only one right answer to the question of how many objects there are. Likewise, the correctness of the result does not depend on how many objects users of each version think there are in a situation. If we take any (scientific) statement referring to any sort of object that is held to be true of a certain situation or physical system, there will be a corresponding statement about the same physical system that groups the elements of the situation according to the norms of mereology, and this latter will be true of the situation iff the former is. The same holds for inferential relations between sets of scientific statements; truth is preserved. Thus both versions are equivalent in expressive power, are fully interpretable in one another and preserve explanatory relations as well as predictive power under transformation. As Putnam says, "the two schemes are in practice thoroughly equivalent" (1992a, p. 116) ${ }^{38}$ But each time the objects of a situation are counted, the result of one version expressed in a sentence like "there are three objects on the table" contradicts the result on the basis of the other expressed in a sentence like "there are seven objects on the table", so that there is no way of joining them in one overarching conception of what 
objects really are. Since knowledge claims remain unaffected by such a decision, for Putnam this means that our knowledge claims do not require any such ontological decision at all. For all we know, the truth-condition for the empirical statement "there are three electrons interacting with the slit" is a situation with three individuals if and only if it is one with seven mereological objects. Certainly these descriptions cannot be taken as falsifying each other in any environment-related sense. Moreover, this equivalence is itself the outcome of judging the result of simultaneously applying the respective descriptions to situations in the environment (i.e., a result obtained within a practice of making and evaluating empirical statements).

Putnam suggests that similar cases of conceptual relativity are available in standard scientific practice (often referred to as "dualities"). For example, he points to the field/particle duality in quantum mechanics and the geometrical duality between taking points as particulars or as limits of extended structures. Each case generates a surface contradiction in the description of ontological commitments (fields or particles, points or lumps), while both descriptions applied to empirical circumstances are factually equivalent in the mentioned sense. In these cases one could say (although Putnam does not put it like this) that the subject matter of inquiry can be multiply constituted from different bases without this having any effect on the available knowledge or the determinacy of the claims that are exchanged. The phenomena of conceptual relativity could thus be understood as instances where a body of empirical statements (or theoretical structures) can be embedded in different (i.e., nonconjoinable) background ontologies without loss or gain. ${ }^{39}$

Putnam's use of conceptual relativity subverts realists who want to defend the picture of a uniquely structured realm of underlying reality as a precondition for the objectivity of our claims. The symmetries between the descriptions in cases of conceptual relativity show that the determinacy of our claims does not depend on the supposition that the question "Which of the two ontologies should we prefer?" be answerable in a definitive or nonarbitrary way. Indeed, there can be neither empirical nor even practical reasons to prefer one to the other. If there were reasons at all, they would have to be conventional (i.e., social reasons). Thus the realist must be prepared to say that the objectivity of our claims is grounded in one fixed, uniquely structured realm, and that this realm is chosen by social convention! That reductio shows that our practices of making empirical claims and taking them to be objectively correct descriptions of a publicly accessible environment do not presuppose any such superthing. Each claim does presuppose a variously accessible, richly conceptualized and sometimes 
multiply organizable local environment for its evaluation, an environment that, for all these reasons, can be common to many differently predisposed human beings. This is, roughly, where Putnam started his development, which in many ways has been a "journey from the familiar to the familiar" (1994b, p. 300).

\section{Notes}

1. Putnam calls this way of situating his philosophical stance explicitly the "supremacy of the agent point of view" (1987, p. 70), and connects it with the pragmatist and Kantian traditions. The expression "participant perspective" was used in Ebbs (1992) in his illuminating analyses of Putnam's views, where it refers to his earlier as well as his later position. In a somewhat different theoretical context, this expression (which calls to mind Dewey's critique of the spectator's perspective) had been in use since the 1970s in the writings of Habermas to distinguish between philosophies produced from the "observer" and "participant" standpoints, where only the latter are able to capture normative elements of the practices at issue in philosophical analysis. A descendant of the latter notion, exploiting its Kantian and pragmatist undertones, has been employed in characterizing Putnam's method (again, early and late) as "presupposition analysis" in Mueller (2001). In this chapter, the term is used generically.

2. Putnam places his current position within the broader framework of a pragmatist philosophy, whereas his earlier writings served to undercut empiricist strategies of explaining knowledge and meaning. So we could conjecture that, according to Putnam, a thoroughly pragmatist point of view is the strongest anti-empiricist stand to take, all things considered. This, in turn, ties in nicely with his recent focus on the weaknesses of reformed empiricism of the Quinean sort and what has come to be called "naturalism".

3. In fact, there is one exception in Putnam's early writings, and this concerns his views on mathematics and logic. In his early writings in the philosophy of mathematics, he decided to follow a "realist" strategy in accepting universals as mathematically real. Realism in these discussions, however, was opposed to nominalism, not to a broader anti-realist point of view. But nominalism and (epistemic) realism are not incompatible, which is why this sense of "realism" will not play a role in our account. (For an early assessment of his own writings in this sense of realism, see $1975 \mathrm{a}$, p. vii. For later remarks to the same effect, see 1992b, pp. 348 ff.) Over time, and because of his conceptual relativity, Putnam's position on the ontological import of mathematics has moved away from this early Quinean stance; for this development see 1994d, pp. 259-260; 1999, p. 179; 2001b, lecture III.

4. Keeping track of this latter point provides one way of understanding the evergrowing differences between Putnam and Quinean naturalism. For these differences see Putnam 1994d, p. 248, and 1992b, p. 402.

5. In his recent work (1998), Putnam explicitly makes the point that this extends to knowledge claims in general. 
6. Quine's position on the issue is further expanded in his (1935) and (1954).

7. This can be seen by the correspondences between the themes he develops at this early stage and claims in his later work, e.g., "'Two Dogmas' Revisited", "Analyticity and Apriority: Beyond Wittgenstein and Quine", and "Convention: A Theme in Philosophy" (all in 1986), as well as 1992b, pp. 391-393, and 1994d, pp. 249-252.

8. In the case of what is nowadays referred to as "folk psychology", he says: "The acceptance of [a] conceptual system, or explanatory scheme, is justified, as is the acceptance of many an empirical hypothesis, by the joint facts of explanatory power and no real alternative" (1969, p. 447).

9. At this point, we can already see that Putnam's reconstruction not only contextualizes the distinctions between analytic and synthetic statements, a priori and empirical claims, conventional and factual elements in the acceptance conditions of beliefs, but also by doing so makes it difficult to see a dramatic difference between internal and external, or, more important, between the procedures guiding decisions in normal or revolutionary changes.

10. A related conception was proposed in Fine 1967. If we conjoin the idea that the semantics of empirical concepts depends on the results of their application to empirical circumstances over time with the idea of "rigidity", we get the Kripke-Putnam theory of natural-kind terms. Applying the semantics of rigidity to live empirical concepts is criticized in Fine 1975, anticipating some of the reasons that led Putnam increasingly to distance himself from Kripke's views on the matter. A more detailed analysis of Putnam's pragmatic account of the semantics of empirical concepts can be found in Mueller 2001, chaps. $8-10$.

11. As Putnam will say later, this way of reconstructing concept-use treats the fact that theories are regarded as successors or competitors and the fact that their basic vocabulary refers to a sufficient amount of shared objects as two ways of making the same point $(1988$, p. 11).

12. Soames attributes to N. Salmon the related idea of law clusters as groups of individually sufficient, but neither jointly nor individually necessary, conditions for the application of a term and develops that notion (Soames 1999, pp. vii and 170ff.).

13. Consider, for example; "the use of the word 'temperature' rests upon the empirical fact that there exists a single physical magnitude ... which is normally responsible for differences in "felt warmness" (1963b, p. 128).

14. Cf. 1963b, p. 130. This is inspired by the results of Ziffs work on semantics and Harris's work on discursive appropriateness and paraphrasability (yielding a pragmatic notion of linguistic synonymy), which Putnam transposes into reference. In fact, it works as a sort of master argument in Putnam's criticism of Feyerabend, conventionalism, and Malcolm. He refers to the principles we are going to discuss in 1959, pp. 209ff.; 1962, pp. 52ff.; and 1962c, pp. $318 \mathrm{ff}$.

15. It should be obvious that by deflecting attention from the question of continuity of beliefs toward continuity of practice and reference, Putnam accomplishes two things: he changes the burden of proof, and he converts what seemed to be a 
global issue into a variety of local questions. Where it seemed that we should justify the continuity of reference through conceptual change, it now appears that what has to be proven is the discontinuity under such conditions.

16. There was a second motivation behind Putnam's turn to metaphysical realism; namely, his political engagement at the time. "The... concerns for a better world, the desire to make my philosophical activity a part of that concern, and the involvement with Marxism ... led me to an increasingly strong metaphysical realism, simply because that position seemed more consistent with Marx's 'dialectical materialism' as I interpreted it" (1992b, p. 350).

17. The quote continues: "in general, and in the long run, correct ideas lead to success, and ideas lead to failures where and insofar as they are incorrect. Failure to see the importance of practice leads directly to failure to see the importance of success."

18. History had it that the term "internal realism" applied to whatever doctrines Putnam came to hold disputing the viability of the explanationist defense. At first, Putnam did not take issue with this "mistake" of his interpreters and in 1981 even used the expression to refer to his own view. As soon as he did, "internal realism", like a character in a serial that begins to be a prison for the author's creativity, was put to rest. Putnam came to share Gary Ebbs's impression (1992) that the character was by now preventing rather than enhancing understanding. The definite burial of the term can be found in his 1992b and 1999, part 1 (the 1994 Dewey lectures). "Pragmatic realism" inherited the fortune. It surfaced, to the best of our knowledge, first in 1987 (p. 17), and then, more prominently, in 1988 (p. 114).

19. Although skeptical worries about this latter possibility work, at the time, as a supplementary motivation for Putnam's beginning to take an explicit position on the issue, we submit that he never seriously entertained, and does not now entertain, the idea that it could be coherent to be convinced that we are engaged in making empirical claims and that versions of (1)-(3), applied to the terms and statements used by us to make the claims, are false. The background reservation is just the thought that we cannot make sense of claims that are empirical but empty (i.e., do not refer at all) or totally indeterminable (do not refer in an evaluable way). The dramatized version of the skeptical worry is the "disastrous meta-induction": "What if all the theoretical entities postulated by one generation ... invariably "don't exist" from the standpoint of later science?... just as no term used in the science of more than fifty (or whatever) years ago referred, so it will turn out that no term used now ... refers. ... But what happens to the notion of truth in theoretical science if none of the descriptive terms refer? Perhaps all theoretical sentences are "false"; or some convention for assigning truth-values when predicates don't refer takes over" (1978, p. 25).

20. The step according to which the described entity just is the objective entity is obviously subject to the same difficulty, since its warrant could only consist in another cognition of the entity in question.

21. This is how we understand his consistent emphasis that the outcome of his anti-verificationism, namely his (and Kripke's) theory of reference and his semantic externalism, does not provide necessary and sufficient conditions for 
(or reductions of reference to) something else (e.g., causality), but presupposes it. See 1974 b, p. 286 , and 1978 , p. 58 , where he says that he would rather call the "causal" theory of reference the "social co-operation plus contribution of the environment theory of the specification of reference". The same idea recurs later in 1992, pp. 23, 165, 211, and passim. See his 1990b for his repudiation of Kripke's metaphysical reading of reference. Mueller 2001, chap. 10, stresses the pragmatic character of Putnam's externalism.

22. We want to emphasize (and this speaks for continuity in his outlook) that Putnam himself repeatedly stresses that his experiment with a more substantive version of realism than the one required by his pragmatic outlook was rather uncomfortable for him. See 1988, pp. xii and 107, where he describes his relation to scientific realism as an "approach-avoidance conflict", and 1999, where he speaks of having been caught in "antinomies" he saw no way to reconcile, and began "recoiling" from one extreme to the other (see esp. pp. 12-16).

23. This line of argument is in Williams 1986.

24. With a Darwinian twist, this is van Fraassen's way of defusing the success argument (1980, pp. 39-40). Of course, saying that it depends on us (is one of our norms) to only admit theories we regard as successful does not at all mean that we make the theories successful.

25. This is not scientism, but simply a fact of about how science enters our lives. Thus, Putnam's division of linguistic labor (cf. 1975c, pp. 227ff.) stresses that we often defer to scientists to improve our reasoning in the process of making certain decisions about reference. The reason is not the technocratic one, that scientists are more competent about fixing extensions of our terms, but the fact that the right scientists know a lot about, for example, gold and how to find out whether something is gold (cf. 1988, pp. 22-26).

26. The dialectic of the inner and outer is elaborated for both realism and antirealism in (Fine, 1996a, chaps. 7 and 8; see especially chap. 8 for some criticisms of the explanationist defense that we draw on below).

27. In spite of Putnam's dismissal of instrumentalism (1981, pp. 38-39), this is quite in line with the epistemological aspect of his model-theoretic argument (in 1976b and 1977); see 1992b, pp. 345-355.

28. Compare Putnam 1976b, pp. 126-129 as well as 1994b, 302-304 on the upshot of his model-theoretic argument. See also the "metatheorems" in Fine 1986 and 1996a, pp. 180-186.

29. This nagging question accompanies Putnam's reflections on the explanationist defense from early on, in his 1978 and 1981.

30. See Levin 1984 and Williams 1986; also Putnam 1999, pp. 55-56.

31. See the discussion of "truthmongers" in Fine 1996a, chap. 8 for a critique of this identification that connects it with a general form of behaviorism.

32. In an interesting twist, Putnam turns the grammaticality of the claim that we have no access to reality as it is against those (like Rorty) who want to say that there is nothing but discourse: "if we agree that it is unintelligible to say, 'We sometimes succeed in comparing our language and thought with reality as it is in itself', then we should realize that it is also unintelligible to say 'It is impossible to 
stand outside and compare our thought and language with the world'" (1994b, p. 299).

33. See also 1992 b, pp. 355, 366-368.

34. See, too, his discussion with Rorty on the nature of assertibility-conditions in (1995, pp. 32-38). For a connection with the "unforced judgments" that are at the heart of social constructivism, see Fine 1996b.

35. Recall an earlier Putnam, "as thinkers we are committed to there being some kind of truth, some kind of correctness which is substantial and not merely 'disquotational'" (1981, p. 21), and more adamantly in 1994a, chaps. 13 and 16. The dismissals of disquotationalism in these articles now have to be qualified. In his 2001a, Putnam therefore chooses to specify his view as a sort of disquotationalism (rather than 'deflationism', which he associates with verificationism).

36. This does not mean, of course, that they generalize in the same directions everywhere else - i.e., allow for global mutual or even only one-way reduction ("perfect extensional translation"). It seems to be precisely one of the points of Putnam's pluralism that they do not, but that this does not prevent users of such descriptions from developing local agreements of truth. The idea of comparing theories by means of locally overlapping extensions was explored in Fine 1975.

37. Putnam clearly notices this means that, in these cases, we ought to abandon the usual notion of synonymy as a constraint on successful interpretation, since the correlated sentences are not synonymous in any straightforward sense, in spite of the fact that they can make an equivalent contribution to the communicative success of their users; see his 1992a. It would be hasty, though, to sum this up in the fashionable turn of phrase that Putnam "overcomes representationalism", as his construction makes and requires the clear distinction between sign and object presupposed in ordinary referential semantics, and the outcome of his construction is that, while the users of various descriptions may be referring to different objects, they can still represent the same situation (much like a live-TV report and a flight-number-space-time matrix can represent the same plane).

38. For a more detailed account of this see Putnam 1980.

39. A useful discussion of these questions can be found in Case 1997. For an account of the parallelism between producing conceptual relativity and revising redescriptions in fallibilistic practices of evaluation see Mueller 2002 and Mueller, forthcoming.

\section{References}

Case, J. (1997). "On the Right Idea of a Conceptual Scheme”. Southern Fournal of Pbilosopby 35:1-18.

Ebbs, G. (1992) "Realism and Rational Inquiry”. Philosophical Topics 20:1-33. (2001). "The Very Idea of Sameness of Extension across Time". American Philosophical Quarterly 37:245-268.

Fine, A. (1967). "Consistency, Derivability, and Scientific Change". Fournal of Philosophy 64:231-240. 
(1975). "How To Compare Theories: Reference and Change". Nous 9:17-32.

(1986). "Unnatural Attitudes: Realist and Antirealist Attachments to Science". Mind 95:149-177.

(1996a). The Shaky Game: Einstein, Realism, and the Quantum Theory. 2nd ed. Chicago: University of Chicago Press.

(1996b). "Science Made Up: Constructivist Sociology of Scientific Knowledge". In P. Galison and D. Stump (eds.), The Disunity of Science: Boundaries, Contexts, and Power: Stanford, CA: Stanford University Press, pp. 231-254.

Levin, M. (1984). "What Kind of Explanation Is Truth?” In J. Leplin (ed.), Scientific Realism. Berkeley: University of California Press, pp. 124-139.

Mueller, A. (2001). Referenz und Fallibilismus. Berlin/New York: DeGruyter.

(2002). "Putnams pragmatischer Kognitivismus". In M. Willaschek and M. L.

Rater (eds.), Hilary Putnam und die Tradition des Pragmatismus. Frankfurt: Suhrkamp, pp. 65-87.

(forthcoming). "Conceptual Relativity, Semantic Contextualism and Fallibilism". Teorema.

Peirce, C. S. (1868). "Some Consequences of Four Incapacities". In Philosophical Papers 5.264-314.

Putnam, H. (1959). “Memo on 'Conventionalism'”. In Putnam 1975, pp. 206-214.

(1960). "Minds and Machines". In Putnam 1975b, pp. 362-385.

(1962a). "The Analytic and the Synthetic". In Putnam 1975b, pp. 33-69.

(1962b). "It Ain't Necessarily So". In Putnam 1975, pp. 237-249.

(1962c). "Dreaming and 'Depth Grammar'”. In Putnam 1975b, pp. 304-324.

(1963a). “An Examination of Grünbaum's Philosophy of Geometry”. In Putnam 1975, pp. 93-129.

(1963a). "How Not To Talk About Meaning". In Putnam 1975b, pp. 117-131.

(1963b). "Brains and Behavior". In Putnam 1975b, pp. 325-341.

(1965). "Philosophy of Physics". In Putnam 1975, pp. 79-93.

(1969). "Logical Positivism and the Philosophy of Mind". In Putnam 1975b, pp. $441-451$.

(1974a). "The 'Corroboration' of Theories”. In Putnam 1975, pp. 250-269.

(1974b). "Language and Reality". In Putnam 1975b, pp. 272-290.

(1975a). Philosophical Papers I. Mathematics, Matter and Method. Cambridge: Cambridge University Press.

(1975b). Philosophical Papers II. Mind, Language, and Reality. Cambridge: Cambridge University Press.

(1975c). "The Meaning of 'Meaning'”. In Putnam 1975b, pp. 215-271.

(1975d). "What Is Mathematical Truth?". In Putnam 1975, pp. 60-78.

(1976a). "Reference and Understanding". In Putnam 1978, pp. 97-122.

(1976b). "Realism and Reason". In Putnam 1978, pp. 123-138.

(1977). "Models and Reality". In Putnam 1983, pp. 1-25.

(1978). Meaning and the Moral Sciences. London: Routledge and Kegan Paul. 
(1980). "Equivalence". In Putnam 1983, pp. 26-45.

(1981). Reason, Truth, and History. Cambridge: Cambridge University Press.

(1982a). "Three Kinds of Scientific Realism". In Putnam 1994a, pp. 492-498.

(1982b). “A Defense of Internal Realism”. In Putnam 1990, pp. 30-42.

(1983). Philosophical Papers III. Realism and Reason. Cambridge: Cambridge University Press.

(1987). The Many Faces of Realism. LaSalle, IL: Open Court.

(1988). Representation and Reality. Cambridge, MA: MIT Press.

(1990a). Realism with a Human Face, Cambridge, MA: Harvard University Press. (1990b). "Is Water Necessarily $\mathrm{H}_{2}$ O?”. In Putnam 1990a, pp. 54-79.

(1992a). Renewing Philosophy. Cambridge, MA: Harvard University Press.

(1992b). "Replies." Philosophical Topics 20,1:347-408.

(1994a). Words and Life. Cambridge, MA: Harvard University Press.

(1994b). “The Question of Realism”. In Putnam 1994a, pp. 295-312.

(1994c). "Realism without Absolutes". In Putnam 1994a, pp. 279-294.

(1994d). "Rethinking Mathematical Necessity". In Putnam 1994a, pp. 245-263.

(1994e). "Comments and Replies". In P. Clark, and B. Hale (eds.), Reading Putnam.

Oxford: Blackwell, pp. 242-302.

(1995). Pragmatism. An Open Question. Oxford: Blackwell.

(1998). "Skepticism". In M. Stamm (Ed.), Philosophie in synthetischer Absicht. Stuttgart: Klett-Cotta, pp. 238-268.

(1999). The Threefold Chord. Mind, Body, and World. New York: Columbia University Press.

(2001a). "Concluding Remarks and Reply to Juergen Habermas". Manuscript. Published in German as "Antwort aufJürgen Habermas," in M. Willaschek and M. L. Rater (eds.), Hilary Putnam und die Tradition des Pragmatismus. Frankfurt: Suhrkamp, 2002, pp. 306-321.

(2001b). "The 2001 Hermes Lectures, held in Perugia (Italy)". Manuscript.

(2002). "Pragmatism and nonscientific knowledge". In J. Conant and U. Zeglen (eds.), Hilary Putnam: Pragmatism and Realism. London/New York: Routledge, pp. 14-24.

Quine, W. V. O. (1935). “Truth by Convention”. In Quine 1976, pp. 77-106.

(1951). "Two Dogmas of Empiricism". In Quine 1980, pp. 20-46.

(1954). “Carnap and Logical Truth”. In Quine 1976, pp. 107-132.

Soames, S. (1999). Understanding Truth. Oxford: Oxford University Press.

van Fraassen, B. (1980). The Scientific Image. Oxford: Clarendon Press.

Williams, M. (1986). "Do We (Epistemologists) Need a Theory of Truth?" Philosophical Topics 14:223-242. 